\title{
Randomized control trial to compare the effectiveness of mifepristone followed by misoprostol at 12 hours interval versus misoprostol alone in second trimester medical termination of pregnancy
}

\author{
Preet Kamal Bedi, Arunima Saini*
}

Department of Obstetrics and Gynecology, Government Medical College, Amritsar, Punjab, India

Received: 05 June 2018

Accepted: 29 June 2018

*Correspondence:

Dr. Arunima Saini,

E-mail: arunima0123@gmail.com

Copyright: () the author(s), publisher and licensee Medip Academy. This is an open-access article distributed under the terms of the Creative Commons Attribution Non-Commercial License, which permits unrestricted non-commercial use, distribution, and reproduction in any medium, provided the original work is properly cited.

\section{ABSTRACT}

Background: Mifepristone priming in second trimester abortions not only decreases the induction-abortion interval (IAI) but also lessens the total misoprostol dose required and hence reduces adverse effects. The present study aims to compare the role of mifepristone priming 12 hours before misoprostol administration so as to increase patient compliance and shorten the duration of hospital stay.

Methods: This prospective study was conducted over a period of one year, on 50 patients requiring second trimester abortion, at Department of Obstetrics and Gynaecology, Government Medical College, Amritsar. The patients were divided into two groups with 1:1 randomization. In Group A, 25 women were given tablet mifepristone $200 \mathrm{mg}$ orally followed 12 hours later by tablet misoprostol $400 \mu \mathrm{g}$ per vaginum followed by the same dose 3 hourly for a maximum of five doses per 24 hours. In group B, 25 women received only tablet misoprostol $400 \mu \mathrm{g}$ vaginally in the posterior fornix followed by the same dose 3 hourly for a maximum of five doses per 24 hours. Primary outcome was to compare the completeness of expulsion of products of conception by pelvic ultrasound after 48 hours of the last dose administered. Secondary outcome was to compare the Induction abortion interval (IAI), mean dose of misoprostol required, side effects, effect of parity, gestational age and cervical dilatation on IAI with both the regimens used.

Results: The success rate was $76 \%$ in group A and $64 \%$ in group B. The mean induction abortion interval in group A was 8.9 \pm 4.70 hours whereas in group B, it was $13.14 \pm 6.03$ hours and this difference was statistically significant ( $\mathrm{p}=$ 0.008). A statistically significant difference was also observed in mean dose of misoprostol required in group A and B being $1232.00 \pm 398.60 \mu \mathrm{g}$ and $1584.00 \pm 423.94 \mu \mathrm{g}$ respectively $(\mathrm{p}=0.004)$. The side effects were less in group A. Parity and cervical dilatation hold an inverse relation with the mean IAI whereas it has a direct relation with the gestational age.

Conclusions: Regimen involving mifepristone priming 12 hours before misoprostol is better than misoprostol alone regimen with significant reduction in IAI, mean dose of misoprostol and less side effects.

Keywords: Mifepristone, Misoprostol, Second trimester abortions

\section{INTRODUCTION}

Second trimester abortions constitute $10-15 \%$ of all induced abortions worldwide. ${ }^{1}$ A variety of methods were used in the past for second trimester medical termination of pregnancy which included extraovular (extraamniotic) normal saline instillation, extraamniotic injection of ethacridine lactate, laminaria tent, intraamniotic instillation of $40 \%$ formalin ( $3 \mathrm{cc}$ ), intraamniotic injection of $20 \%$ hypertonic saline and the use of bougies. 
These methods had life threatening complications like disseminated intravascular coagulation, thromboembolism, cerebral infarction, acute renal failure making them unsuitable for use. .,3 $^{2,}$

The ideal second trimester abortion method aims at a procedure that is both simple and safe with minimum incidence of side effects and has a high success rate within a minimum span of use. For abortion at 13-24 weeks of gestation, medical abortion with mifepristone followed by a prostaglandin (PG) analogue is an appropriate method and has shown to be effective., Prostaglandins act on the myometrium and initiate a wave of violent contraction. Pike and Corey were the first to publish about the chemical synthesis of prostaglandins. ${ }^{6}$

Misoprostol, a synthetic prostaglandin E1 (PGE1) analogue, was developed for the prevention and treatment of peptic ulcer caused by prostaglandin synthase inhibitors (Lewis, 1985). When misoprostol is given orally, the levels of misoprostic acid peak between 12.5 to 60 minutes of administration and fall steeply by 120 minutes. But those receiving vaginal dose, the levels rise gradually and reach maximum levels between 60 to 120 minutes and decline slowly. This difference is because of presystemic gastrointestinal and hepatic metabolism that occurs only with oral administration of drug (Tang et al). ${ }^{7}$

Mifepristone, a steroidal antiprogestogen, blocks the progesterone receptors resulting in vascular damage, decidual necrosis and bleeding which leads to cervical softening, increased uterine sensitivity to prostaglandins and conversion of the quiet pregnant uterus into an organ of spontaneous activity with maximal effect at 36-48 hours. The peak plasma concentrations of $1.9 \pm 0.8$, $3.8 \pm 0.9$ and $5.3 \pm 1.3 \mu \mathrm{mol} / 1$ are reached within $1-2$ hours after oral administration of 50, 200 and $600 \mathrm{mg}$ mifepristone respectively, in women and are maintained at relatively high levels upto 48 or 72 hours depending on the ingested dose. ${ }^{8}$

Norman et al reported that mifepristone given 48 hours prior to misoprostol enhances the stimulatory effect of misoprostol on uterine muscles resulting in increased frequency of contractions. ${ }^{9,10}$ This $36-48$ hours interval is too long and it increases the duration of treatment, repeated visits to the hospital and a possibility that a woman may change her mind in the time interval between the administration of two drugs and thereby discontinue midway. The present study aims to compare the role of mifepristone priming 12-hours before misoprostol administration so as to increase patient compliance and shorten the duration of hospital stay.

\section{METHODS}

This prospective, single center, randomized control trial was conducted over a period of one year (June 2016 to June 2017), on 50 patients coming in need of Second trimester abortion, at Department of Obstetrics and
Gynaecology, Bebe Nanki Mother and Child Care Centre, Government Medical College, Amritsar. The patients were divided into two groups with 1:1 randomization. The gestational age was determined by the history, clinical and ultrasonographic report. A written informed consent was taken from all the patients after obtaining approval from the institutional ethical committee. As per the guidelines of MTP Act 1971, the patients between 13-20 weeks of pregnancy fulfilling the following inclusion and exclusion criteria were enrolled in this study.

\section{Inclusion criteria}

- 13 to 20 weeks of gestation

- Gross congenital malformations not compatible with life

- Conception as a result of failure of contraception

- Rape victims

- Missed abortions

- Grave medical disorders in mother

- Obstetrical indications

\section{Exclusion criteria}

- Grand multipara.

- Ectopic pregnancy

- Scarred uterus

- History of thromboembolism or liver disease

- Heavy smoker of $>20$ cigarettes/day

- Renal disease

- Severe uncontrolled bronchial asthma

- Incomplete abortions

In group A, 25 women were given tablet mifepristone $200 \mathrm{mg}$ and asked to return to hospital 12 hours later for misoprostol administration, when tablet misoprostol 400 $\mu \mathrm{g}$ was given vaginally followed by $400 \mu \mathrm{g}$ vaginal misoprostol every 3 hours for a maximum of five doses per 24 hours.

In group B, 25 women received only tablet misoprostol $400 \mu \mathrm{g}$ vaginally in the posterior fornix followed by 400 $\mu \mathrm{g}$ vaginal misoprostol every 3 hours for a maximum of five doses per 24 hours.

In both the groups, injection tetanus toxoid was given to all the patients and injection anti-D 300 $\mu \mathrm{g}$ intramuscularly if patient was $\mathrm{Rh}$ negative. Temperature, pulse rate, blood pressure and respiratory rate charting was maintained four hourly. Patients were observed for any side effects of drugs like fever, vomiting, chest pain, diarrohea. A follow-up pelvic ultrasound scan after 48 hours of last dose of tablet misoprostol was done for all the patients in both the groups.

Primary outcome was to compare the completeness of expulsion of products of conception by pelvic ultrasound after 48 hours of the last dose administered. Patients with 
retained products of conception on ultrasound were taken as a failure case.

Secondary outcome was to compare the Induction abortion interval (IAI), doses of misoprostol required, side effects, effect of parity, cervical dilatation and gestational age on IAI with both the regimens used. Success was defined by complete expulsion of conceptus confirmed by ultrasound report.

Failure was defined by retained products of conception on ultrasound report and clinically demonstrable failed expulsion of conceptus within the stipulated time i.e $>15$ hours of the first dose of misoprostol in both the regimens.

\section{Statistical analysis}

Data thus obtained was analyzed by Statistical Package for Social Sciences (SPSS) version 23. Unpaired t test was used to compare different variables between two groups. $\mathrm{P}$ value of $<0.05$ was taken as statistically significant.

\section{RESULTS}

Mean age in group A was $24.30 \pm 2.52$ years and in group B was $25.92 \pm 3.45$ years but no statistical significance was observed in the two groups in relation to the mean age of the patients $(\mathrm{p}=0.06)$ (Table 1$)$.

Table 1: Basic parameters studied in the two groups.

\begin{tabular}{|lllll|}
\hline Parameters & Mean age & Mean gravidity & Mean parity & Mean gestational age \\
\hline Group A & $24.30 \pm 2.52$ & $1.85 \pm 1.45$ & $0.74 \pm 1.1$ & $17.50 \pm 2.50$ \\
\hline Group B & $25.92 \pm 3.45$ & $2.44 \pm 1.22$ & $0.96 \pm 0.93$ & $16.02 \pm 2.96$ \\
\hline P value & 0.06 & 0.13 & 0.44 & 0.06 \\
\hline Significance & Non-significant & & & \\
\hline
\end{tabular}

Table 2: Induction-abortion interval (IAI) in the two study groups.

\begin{tabular}{|lllll|}
\hline \multirow{2}{*}{ IAI } & Group A & \multicolumn{2}{c|}{ Group B } \\
\hline 0-3hrs & No. & \% & No. & \% \\
\hline 3-6hrs & 00 & 0 & 00 & 0.0 \\
\hline 6-9 hrs & 09 & 36.0 & 05 & 20.0 \\
\hline 9-12 hrs & 10 & 40.0 & 09 & 36.0 \\
\hline 12-15 hrs & 04 & 56.0 & 02 & 8.0 \\
\hline >15hrs (failure) & 0 & 00 & 04 & 16.0 \\
\hline Mean IAI (Hrs) & $8.9 \pm 4.70$ & & $13.14 \pm 6.03$ \\
\hline p value & 0.008 & & & \\
\hline Significance & Significant & & \\
\hline
\end{tabular}

In group A, 64\% (16 out of 25) patients were primigravida, $16 \%$ (4 out of 25 ) were second gravid, $4 \%$ ( 1 out of 25 ) were third gravida and $16 \%$ (4 out of 25 ) were above third gravid. The mean gravidity was $1.85 \pm 1.45$. In group B, $28 \%$ (7 out of 25 ) patients were primigravida, $20 \%$ (5 out of 25 ) were second gravida, $40 \%$ (10 out of 25 ) were third gravida, and $12 \%$ (3 out of $25)$ were above third gravida. The mean gravidity was $2.44 \pm 1.22$. However, no statistical significance was observed between the groups in relation to gravidity of the patients $(\mathrm{p}=0.13)$ (Table 1$)$.

The mean parity was $0.74 \pm 1.1$ in group A and $0.96 \pm 0.93$ in group B. However, no statistical significance was observed in the two groups in relation to parity. In group A, $52 \%$ (13 out of 25) patients presented between 18-20 weeks of gestation, $32 \%$ ( 8 out of 25 ) presented between
13-15.6 weeks and $16 \%$ (4 out of 25 ) between 16-17.6 weeks of gestation. The mean gestational age in this group was $17.50 \pm 2.50$ weeks. In group B, $36 \%$ (9 out of 25) of the patients presented between 13-15.6 weeks of gestation, 24\% (6 out of 25) presented between 16-17.6 weeks and $40 \%$ (10 out of 25 ) between 18-20 weeks of gestation. The mean gestational age in this group was $16.02 \pm 2.96$ weeks. However, no statistical significance was observed between the groups in relation to the gestational age $(\mathrm{p}=0.06)$ (Table 1$)$.

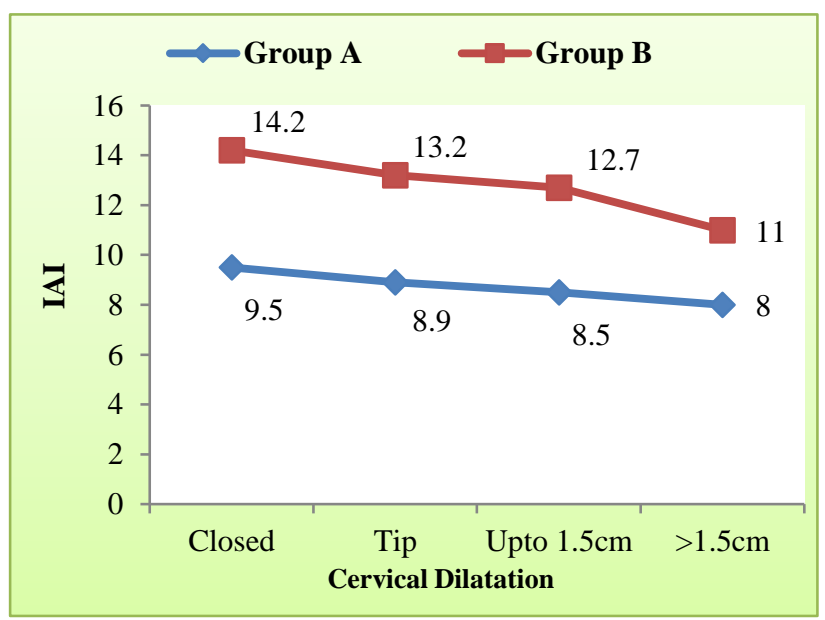

Figure 1: Relation of cervical dilatation with IAI.

The minimum gestation was 13 weeks and maximum was 20 weeks in both the groups. The mean inductionabortion interval was $8.9 \pm 4.7$ hours in Group A and $13.14 \pm 6.03$ hours in Group B and this difference was 
found to be statistically significant $(\mathrm{p}=0.008)$ (Table 2). An inverse relationship is observed in both groups $\mathrm{A}$ and $\mathrm{B}$ between cervical dilatation and induction-abortion interval (IAI) as depicted in Figure 1.

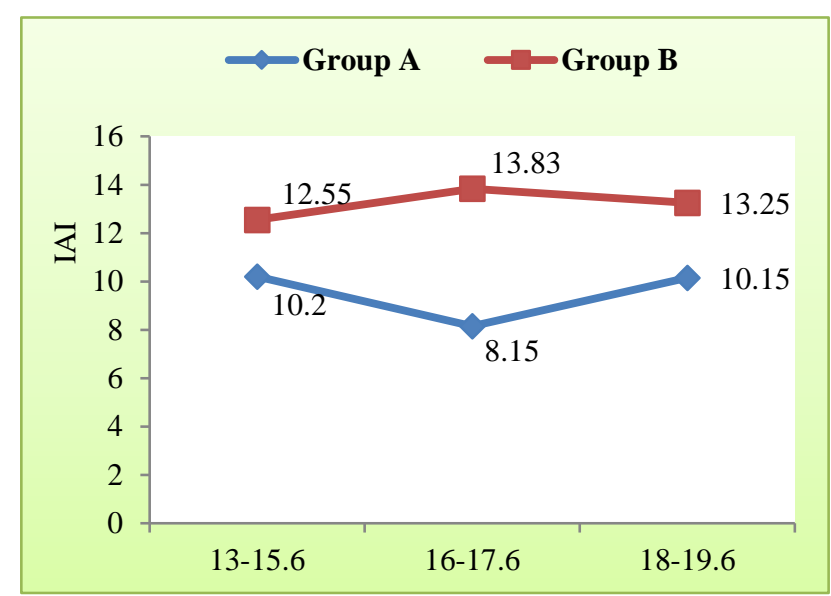

Figure 2: Effect of gestational age on IAI.

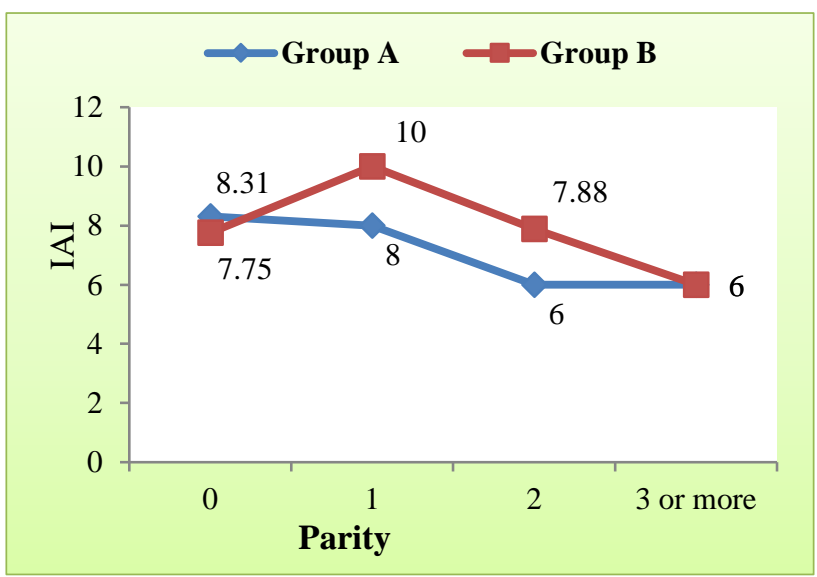

Figure 3: Effect of parity on IAI.

The relationships of gestational age and parity with induction-abortion interval are shown in Figures 2 and 3. The mean dose of misoprostol required was significantly less in group A than in group B in both primigravidas (Table 3) and multigravidas (Table 4).

Table 3: Dose of misoprostol required in primigravida.

\begin{tabular}{|lllll|}
\hline $\begin{array}{l}\text { Total dose } \\
(\mu \mathrm{g})\end{array}$ & \multicolumn{2}{l}{$\begin{array}{l}\text { Group A } \\
(\mathbf{N}=16)\end{array}$} & \multicolumn{2}{l|}{ Group B $(\mathrm{N}=07)$} \\
\hline 400 & No. & $\%$ & No. & $\%$ \\
\hline 800 & - & - & - & - \\
\hline 1200 & 5 & 31.25 & - & - \\
\hline 1600 & 3 & 18.75 & 2 & 28.57 \\
\hline 2000 & 6 & 37.50 & 1 & 14.2 \\
\hline Mean \pm SD & 2 & 12.50 & 4 & 57.1 \\
\hline p value & $1325.00 \pm 431.28$ & $1885.71 \pm 195.18$ \\
\hline Significance & 2.004 & & \\
\hline
\end{tabular}

Table 4: Dose of misoprostol required in multigravida.

\begin{tabular}{|lllll|}
\hline Total dose & \multicolumn{2}{l}{ Group A $(\mathbf{N}=9)$} & \multicolumn{2}{l|}{ Group B $(\mathbf{N}=18)$} \\
\hline$(\mu g)$ & No. & $\%$ & No. & $\%$ \\
\hline 400 & 0 & 0 & 0 & 0 \\
\hline 800 & 4 & 44.4 & 5 & 27.7 \\
\hline 1200 & 4 & 44.4 & 6 & 33.3 \\
\hline 1600 & 1 & 11.2 & 2 & 11.1 \\
\hline 2000 & 0 & 0 & 5 & 27.7 \\
\hline Mean \pm SD & $1066.67 \pm 282.84$ & $1466.66 \pm 433.86$ \\
\hline p value & 0.02 & & & \\
\hline Significance & Significant & & \\
\hline
\end{tabular}

Table 5: Mean dose of misoprostol required in the two study groups.

\begin{tabular}{|lll|}
\hline $\begin{array}{l}\text { Mean dose } \pm \text { SD } \\
(\mu \mathrm{g})\end{array}$ & $\begin{array}{l}\text { Group A } \\
(\mathrm{N}=25)\end{array}$ & $\begin{array}{l}\text { Group B } \\
(\mathrm{N}=25)\end{array}$ \\
\hline Mean & $1232.00 \pm 398.60$ & $1584.00 \pm 423.94$ \\
\hline P value & 0.004 & \\
\hline Significance & Significant & \\
\hline
\end{tabular}

Also, the mean dose of misoprostol required to achieve expulsion irrespective of gravidity of the patient was significantly less in group A as compared to group B with a mean dose of $1232.00 \pm 398.60 \mu \mathrm{g}$ and $1584.00 \pm 423.94$ $\mu \mathrm{g}$, respectively $(\mathrm{p}=0.004)$ (Table 5).

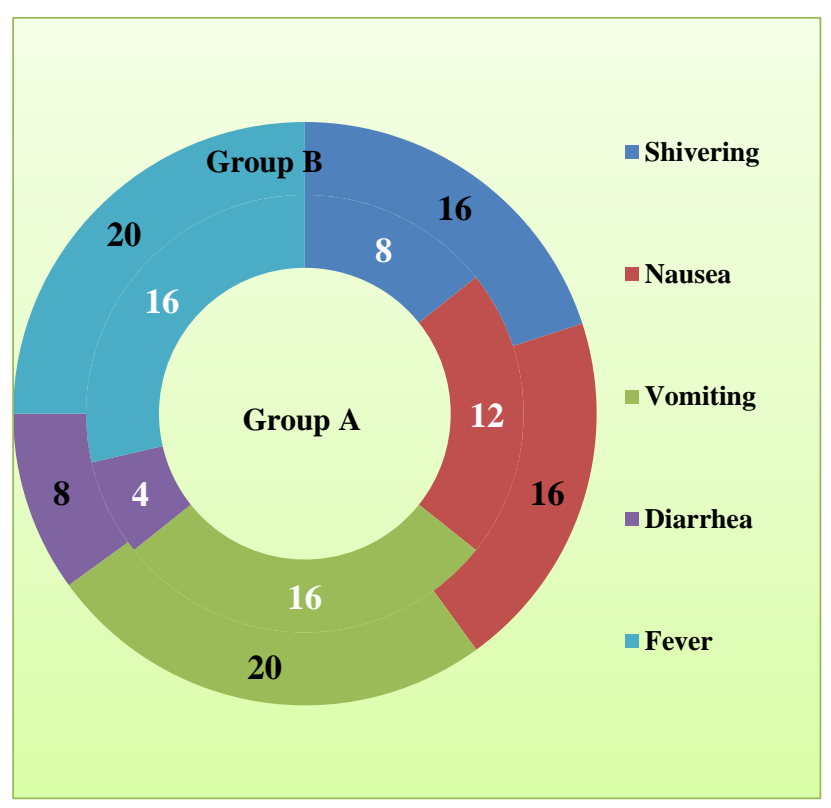

Figure 4: Side effects in both the groups.

Successful expulsion was achieved in $76 \%$ (19 out of 25) patients in group A and 64\% (16 out of 25) in group B. Failure of induction was observed in $24 \%$ (6 out of 25) patients in group A and 36\% (9 out of 25) in group B who were further managed with either evacuation and curettage or intracervical foley's insertion. Side effects of both regimens were almost similar in both the groups with slightly more incidence in group B (Figure 4). 


\section{DISCUSSION}

Misoprostol (PGE1) is the most commonly used drug for second trimester medical abortions. Gastrointestinal side effects are more when the drug is used solely for induction. Mifepristone priming helps not only by significantly decreasing the IAI but also lessens the total misoprostol dose required and hence limiting the side effects. Not only the regimen used determines the IAI, but also the mean gestational age, cervical dilatation and parity change the IAI. Very limited studies have been done on mifepristone priming with 12 hours interval between mifepristone and misoprostol. The reduced interval between the two drugs not only makes it more convenient for the patient but also shortens the duration of hospital stay.

Table 6: Relative comparison of mifepristone priming studies.

\begin{tabular}{|c|c|c|c|c|c|}
\hline $\begin{array}{l}\text { Author name and } \\
\text { year of study }\end{array}$ & $\begin{array}{l}\text { Mifepristone dose } \\
\text { (mg) }\end{array}$ & $\begin{array}{l}\text { Interval } \\
\text { (hours) }\end{array}$ & $\begin{array}{l}\text { Misoprostol } \\
\text { dose }(\mu \mathrm{g})\end{array}$ & $\begin{array}{l}\text { Mean misoprostol } \\
\text { dose }(\mu \mathrm{g})\end{array}$ & IAI \\
\hline Tripti and Namrata ${ }^{11}$ & 200 & 12 & 600,400 & $1186 \pm 291.64$ & $6.72 \pm 2.26$ \\
\hline Chai et al ${ }^{12}$ & 200 & $36-38$ & 600,400 & 1000 & 5.0 \\
\hline Ngoc et al ${ }^{13}$ & 200 & 24 & 400 & 1250 & $8.1 \pm 2.0$ \\
\hline Mukhopadhyay et al ${ }^{14}$ & 200 & 48 & 400,200 & $613 \pm 156$ & 6.62 \\
\hline Kulkarni et a ${ }^{15}$ & 200 & 48 & 400,200 & 600 & 8.15 \\
\hline Patel et $\mathrm{al}^{16}$ & 200 & 24 & 200 & 122 & $18.94 \pm 9.3$ \\
\hline Patil and Biliangady ${ }^{17}$ & 600 & 24 & 600,400 & - & 8.25 \\
\hline Aayushi et al ${ }^{18}$ & 200 & 48 & 400 & 769.89 & 8.12 \\
\hline Present study & 200 & 12 & 400 & $1232.00 \pm 398.60$ & $8.9 \pm 4.70$ \\
\hline
\end{tabular}

Table 6 shows the relative comparison between various studies with varying doses of mifepristone and misoprostol at different intervals. The mean IAI in the present study is in concordance with the findings reported by Ngoc et al, Kulkarni et al, Patil and Biliangady and
Aayushi et al with minor variations although the mean misoprostol dose in the present study was slightly on a higher side. ${ }^{13,15,17,18}$ When the IAI is almost comparable with no major variations, the 12-hour interval regimen takes the advantage of limiting the hospital stay of patient thereby improving compliance.

Table 7: Relative comparison of misoprostol alone studies.

\begin{tabular}{|c|c|c|c|c|}
\hline Author name and year of study & Misoprostol dose $(\mu \mathrm{g})$ & Interval & Mean dose required ( $\mu \mathrm{g})$ & IAI \\
\hline Tripti and Namrata ${ }^{11}$ & 600,400 & 3 & $1736 \pm 320$ & $12.29 \pm 3.14$ \\
\hline Ngoc et al ${ }^{13}$ & 400 & 3 & 1560 & $10.6 \pm 2.5$ \\
\hline Mukhopadhyay et al ${ }^{14}$ & 400,200 & 4 & 870 & $12.19 \pm 3.9$ \\
\hline Kulkarni et al ${ }^{15}$ & 400,200 & 6 & 1600 & $>24.0$ \\
\hline Patel et al ${ }^{16}$ & 200 & 6 & 696 & $24.29 \pm 11.53$ \\
\hline Patil and Biliangady ${ }^{17}$ & 600,400 & 4 & - & $10.99 \pm 3.22$ \\
\hline Aayushi et al ${ }^{18}$ & 400 & 4 & $1043.2 \pm 502.36$ & 13.41 \\
\hline Present study & 400 & 3 & $1584 \pm 423.94$ & $13.14 \pm 6.03$ \\
\hline
\end{tabular}

Table 7 shows the comparison of various studies with misoprostol alone regimen. The mean dose of misoprostol in our study is in concordance with the previous studies conducted by Tripti and Namrata, Ngoc et al, Kulkarni et al and Aayushi et al. ${ }^{11,13,15,18}$ Also, the IAI is almost similar with minor variations.

\section{CONCLUSION}

Present study concluded that regimen A i. e. mifepristone priming 12 hours before misoprostol administration improves the success rate $(76 \%)$ when compared with misoprostol alone $(64 \%)$ regimen. Also, the mean dose of misoprostol required and hence the side effects were lesser when mifepristone priming was done. We could infer that although no major difference was noted in terms of IAI and mean misoprostol dose when mifepristone priming was done at 12 hours interval or a longer interval (as done in other studies), our regimen with 12 hours interval gives a better compliance to the patient with limited hospital stay and least side effects as compared to 36 or 48 hours interval. 
Funding: No funding sources

Conflict of interest: None declared

Ethical approval: The study was approved by the Institutional Ethics Committee

\section{REFERENCES}

1. Gemzell-Danielsson K, Lalitkumar S. Second trimester medical abortion with mifepristonemisoprostol and misoprostol alone: a review of methods and management. Reprod Health Matters. 2008;16(31):162-72.

2. Dass A, Mukhopadahyay P, Dhawan S. Termination of midtrimester pregnancies by intra-amniotic injection of hypertonic saline. J Obstet Gynaecol India. 1975;25(3):323-30.

3. Weinberg PC, Shepard MK. Intraamniotic urea for induction of mid-trimester abortion. Obstet Gynecol. 1973;41(3):451-54.

4. Royal College of Obstetricians and Gynecologists. The care of women requesting induced abortion. evidence-based clinical guideline number 7. RCOG. 2011.

5. World Health Organization. Unsafe abortion: global estimates of the incidence of unsafe abortion and associated mortality in 2000. $4^{\text {th }}$ ed. WHO:Geneva; 2004. Available at http://apps.who.int/iris/bitstream/handle/10665/4297 6/9241591803.pdf;jsessionid=B6AE2F99407F7B725 11A786524B4050D?sequence $=1$

6. Pike JE. Total synthesis of prostaglandins. Fortschr Chem Org Naturst. 1970;28:313-42.

7. Tang OS, Gemzell-Danielsson K, Ho PC. Misoprostol: pharmacokinetic profiles, effects on the uterus and side-effects. Int $\mathrm{J}$ Gynaecol Obstet 2007;99(2):S160-7.

8. Sarkar NN. Mifepristone: bioavailability, pharmacokinetics and use-effectiveness. Eur J Obstet Gynecol Reprod Biol. 2002;101(2):113-20.

9. Norman JE, Thong KJ, Baird DT. Uterine contractility and induction of abortion in early pregnancy by misoprostol and mifepristone. Lancet. 1991;338(8777):1233-6.

10. Baird DT, Norman JE, Thong KJ, Glasier AF. Misoprostol, mifepristone, and abortion. Lancet. 1992;339(8788):313.
11. Nagaria T, Sirmor N. Misoprostol vs mifepristone and misoprostol in second trimester termination of pregnancy. J Obstet Gynaecol India. 2011;61(6):65962.

12. Chai J, Tang OS, Hong QQ, Chen QF, Cheng LN, $\mathrm{Ng}$ E, et al. A randomized trial to compare two dosing intervals of misoprostol following mifepristone administration in second trimester medical abortion. Hum Reprod. 2009;24(2):320-4.

13. Ngoc NT, Shochet T, Raghavan S, Blum J, Nga NT, Minh NT, et al. Mifepristone and misoprostol compared with misoprostol alone for secondtrimester abortion: a randomized controlled trial. Obstet Gynecol. 2011;118(3):601-8.

14. Mukhopadhyay P, Bag TS, Kyal A, Bhuniya A, Saha TK. Second trimester abortion with vaginal misoprostol: is there any advantage with prior mifepristone priming? a comparative study. J South Asian Feder Obst Gynae. 2012;4(1):25-7.

15. Kulkarni KK. Pre-induction with Mifepristone for second trimester termination of pregnancy. J Obstet Gynaecol India. 2014;64(2):102-4.

16. Patel U, Chauhan K, Singhi S, Kanani M. Second trimester abortion-mifepristone and misoprostol or misoprostol alone? Int J Reprod Contracept Obstet Gynecol. 2013;2:315-9.

17. Patil SB, Biliangady HN. A comparative study using combination of Mifepristone and Misoprostol and single drug misoprostol only for second trimester abortion. Sch J App Med Sci. 2014;2(2D):840-3.

18. Kaushal A, Kaur K, Kaur P, Kaur A. Mifepristone plus Misoprostol versus Misoprostol for second trimester termination of pregnancy. Int $\mathrm{J}$ Curr Advanced Res. 2017;6(7):4472-5.

Cite this article as: Bedi PK, Saini A. Randomized control trial to compare the effectiveness of mifepristone followed by misoprostol at 12 hours interval versus misoprostol alone in second trimester medical termination of pregnancy. Int J Reprod Contracept Obstet Gynecol 2018;7:3299-304. 